\title{
Evaluation of Efficiency of Conventional Empirical Antimicrobial Regimen for the Management of Maxillofacial Fascial Space Infection
}

\author{
Al-Mehedi $A^{1}$, Chowdhury $G M^{2}$, Rab $M A^{3}$, Haider $I A^{4}$
}

\begin{abstract}
Introduction: Severe life threatening maxillofacial fascial space infection is caused by wide varieties of aerobic and anaerobic micro organisms. Due to injudicious use of broad spectrum antibiotic therapy and development of resistant microorganisms the conventional empirical antimicrobial therapy is now under threat of treatment failure.
\end{abstract}

Objective: To identify the causative microorganisms of maxillofacial fascial space infections and detection of the effectiveness of conventional antimicrobial agents and find out the most effective empirical antimicrobial regimen against them.

Materials and Methods: This is a descriptive cross-sectional study which was conducted at the Department of Oral and Maxillofacial Surgery in CMH Dhaka and Dhaka Dental College Hospital from 01 July 2012 to 30 June 2013. The study was designed with total 50 patients of maxillofacial fascial space infections. Pus or inflammatory exudates from all those 50 patients were collected with special aseptic precaution in both aerobic and anaerobic conditions. The specimens were sent to microbiological laboratory as soon as possible for culture and sensitivity test both in aerobic and anaerobic conditions. The particulars of the patient and results of the culture and sensitivity tests were recorded in the data sheet of the individual patient. Finally the data were presented in the frequency tables and graphs and analyzed by using a statistical software package SPSS 10.0 version.

Results: As maximum orofacial space infections are caused by mixed microorganisms so it was difficult to treat those by single empirical antibiotic. Even though Clindamycin was found as a single antibiotic to be sensitive in highest $90 \%$ (in 45 patients) cases. Other single effective antibiotics were Erythromycin (50\%) and Azithromycin (40\%).

Conclusion: The study reflects very frustrating and alarming situation regarding the antimicrobial agent sensitivity in the treatment of orofacial space infection. Though less frequently used antibiotics like Clindamycin shown highest sensitivity but merely single broad spectrum antibiotic was effective enough. Empirical antimicrobial therapy could be selected by combination of 2 or more broad spectrum antimicrobial agents.

Key-words: maxillofacial fascial space infection, broad spectrum anti microbial agents, odontogenic and non odontogenic infection, culture and sensitivity test, aerobic and anaerobic bacteria.

\section{Introduction}

The severe life threatening infections involving the potential fascial spaces around the oral cavity and face i.e. in the maxillofacial region is the maxillofacial fascial space infection. Sapiro defined the 'fascial space' as 'potential tissue space, since none are actually spaces until pus has been formed'. These infections are very much dangerous because of strong tendency to spread through the interstitial spaces related to muscular, vascular, nervous and visceral structures and presents clinically as diffuse, painful, indurated, erythematous swellings ${ }^{2}$. Some spreading infections are so devastating that those rapidly and bilaterally involve all the submandibular, sublingual and submental spaces thus creates a severe life threatening cellulitis which is called 'Ludwig's Angina' ${ }^{3}$. These may kill the patients with in short period of time due to suffocation and toxaemia. Untreated or uncontrolled infections may spread from the site of origin to different vital organs from the

1. Lt Col Abdullah Al-Mehedi, BDS, FCPS, Classified Specialist in Oral and Maxillofacial Surgery, CMH, Rangpur 2. Brig Gen Golam Mohiuddin Chowdhury, BDS, FCPS, Adviser Specialist in Dentistry and Oral and Maxillofacial Surgeon, CMH, Dhaka 3. Col Md. Abdur Rab, BDS, FCPS, Classified Specialist in Oral and Maxillofacial Surgery, CMH, Dhaka 4. Dr Ismat Ara Haider, BDS, DDS, MS, Associate Professor and Head, Dept of Oral and Maxillofacial Surgery, Dhaka Dental College Hospital, Dhaka. 
base of the skull to mediastinum and create life threatening complications like cavernous sinus thrombosis, meningitis, epidural or brain abscess, internal jugular vein thrombosis, carotid artery erosion, mediastinitis, pericarditis ${ }^{\mathbf{2 , 4 5 , 6}}$. The characteristic features of these infections depend upon the virulence nature of the causative organisms. Certain micro-organisms produce spreading type infections whilst others produce localized infections. For example, some streptococci produce hyaluronidase, an enzyme which dissolves the intercellular cement substance and fibrinolysin, an enzyme which breaks down fibrin. The presence of this substance in the infected tissues facilitates the spread of the inflammatory process. On the other hand, some staphylococci produce a substance called coagulase, which produces fibrin from plasma and tends to localize the inflammatory lesion. So sometimes the infection primarily appears as cellulitis and progressively spreads to adjoining spaces until and unless arrested by host defense mechanism or secondarily infected by coagulase producing microorganisms and becomes localized and chronic $^{7}$. But if it is caused by staphylococci like microorganisms it primarily appears as a localized painful abscess and then spreads to adjoining spaces either by increased hydrostatic pressure of overwhelming pus or by secondarily infected by hyaluronidase and fibrinolysin producing microorganisms $^{6}$. With the invention of wide varieties of antimicrobial agents the mortality due to maxillofacial fascial space infection has been reduced. Although the incidence of maxillofacial fascial space infection has decreased in recent years in developing countries as a result of improvements in orodental and general health care but these are much common among our mass population due to neglected oral hygiene, malnutrition and increased prevalence of immunosuppressive diseases or disorders like diabetes mellitus, anaemia, malnutrition etc ${ }^{8,9,10,11,12}$. Ninety percent space infections are of odontogenic origin and rest $10 \%$ may have different causes $^{3,13,14,15}$. So most of the times the infections are caused by endogenous mixed and multiple organism with different characteristics ${ }^{3,16,17}$. Most commonly found microorganisms are Gram- positive obligatory aerobic cocci like Streptococcus viridians, Streptococcus pyogenes, Staphylococcus aureus,
Gram-positive facultative anaerobic cocci like Streptococcus viridans, Streptococcus mutans, Stretococcus pneumoniae, Peptostreptococcus, Gram-negative aerobic bacilli like Haemophilus influenza, Escherichia coli, Klebsiella, Gramnegative anaerobic bacilli like Bacteroides fragilis, Bacteroides melaninogenicus and other Bacteroides, Porphyromonas, Prevotella, Fusobacterium nucleatum, fusobacterium mortiferum, Fusobacterium varium and other Fusobacterium, Bacteroides fragilis etc $^{2,3,5,14,18}$. These infections are mostly treated by incision and drainage, antimicrobial therapy and removal of the cause or debridement ${ }^{17}$ as the causative organisms are known, these life threatening infections are treated by blind therapy with broad spectrum antimicrobial agents like penicillin, cephalosporin, metronidazole etc without the culture and sensitivity test ${ }^{3}$. But irrational use of antibiotics or long term administration of same antibiotic for same disease may become ineffective due to the production of resistant organisms. For example 20 years after the invention of penicillin; bacteria like Staphylococcus aureus were capable to achieve resistance capability against it by production of beta lactamase enzyme to destroy the beta lactum chain of penicillin. Few anaerobes like Bacteroides, Fusobacterium, Porphyromona, Provotella also have the capability to produce beta lactamse to acieve resistance against penicillins, cephalosporine, cephamycin, and carbapenems ${ }^{19,20}$. Bacteria possess tremendous capability to change their microbiological pattern to adapt themselves in adverse environment. So it is important to study periodically the microbiological pattern of specific infections and review the routine antibiotic regimen for the treatment of those ${ }^{21}$. In tertiary hospitals where microbiological investigation facilities are available, it is possible to do the culture and sensitivity test of pus or inflammatory exudates of maxillofacial fascial space infection patients to detect the responsible microorganisms and most effective antimicrobial agents to treat them. Thus it will also help to detect the common organisms responsible for maxillofacial fascial space infections in most cases and to review the effectiveness of conventional antimicrobial therapy or identify cost effectiveness at antimicrobial regimen for the treatment of routine maxillofacial fascial space infection of odontogenic origin. 


\section{Materials and Methods}

It is a descriptive cross sectional study performed at two referral hospitals, Combined Military Hospital Dhaka and Dhaka Dental College Hospital Dhaka. The study was conducted in between July 2012 to June 2013. Total 50 patients of maxillofacial fascial space infections who gave the consent to be included in the study were selected for the study. Patients who were non-cooperative and refused to attend for regular follow up were excluded from the study. After recruitment of the patients at first pus or inflammatory exudates was collected and preserved carefully both aerobic and anaerobic condition in room temperature with proper aseptic precautions for culture and sensitivity test. Separate sterile containers were used for anaerobic and aerobic cultures. For anaerobic culture absolute anaerobic environment was strictly maintained either by candle jar or vacuum desiccators. The specimens were sent within sealed tube with water proof tape as soon as possible. Then inflammatory or pus exudates drainage was done and the patients were treated first by conventional broad spectrum antimicrobial agents then switched over to the specific antimicrobial agents according to the culture and sensitivity test report. Data were recorded by making standard data sheet, presented in the frequency tables and graphs and analyzed by using a statistical software package SPSS 10.0 version.

\section{Results}

All patients in this study underwent surgical incision and drainage in the operating room. Patient characteristics reviewed were age, gender, fascial space(s) involved, bacteria identified, and antibiotic resistance from culture and sensitivity tests.

Table-I: Distribution of age group of the study population $(n=50)$

\begin{tabular}{|l|c|c|c|}
\hline $\begin{array}{l}\text { Age group } \\
\text { (Age in year) }\end{array}$ & $\begin{array}{c}\text { Number of } \\
\text { patients }\end{array}$ & $\begin{array}{c}\text { Percentage } \\
\text { frequency }\end{array}$ & $\begin{array}{c}\text { Cumulative } \\
\text { Percentage }\end{array}$ \\
\hline $15-25$ & 18 & $36 \%$ & 36 \\
\hline $26-35$ & 13 & $26 \%$ & 62 \\
\hline $36-45$ & 07 & $14 \%$ & 76 \\
\hline $46-55$ & 06 & $12 \%$ & 88 \\
\hline $56-65$ & 06 & $12 \%$ & 88 \\
\hline Total $(\mathrm{n})$ & 50 & $100 \%$ & 100 \\
\hline
\end{tabular}

Table-I shows distribution of age group of the study population. Among the 50 patients, highest 18 (36\%) were between 15-25 years. Mean age was 34.18 and standard deviation (SD) was 14.37.

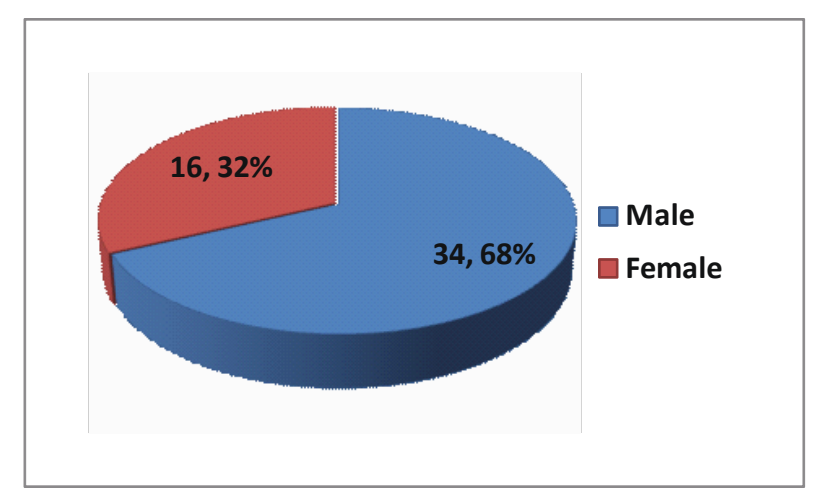

Fig-1: Sex distribution of the study population $(n=50)$

Fig-1 shows sex distribution of the study group. Among the 50 patients $34(68 \%)$ were male and 16 $(32 \%)$ were female. Male: female ratio was 17: 8 .

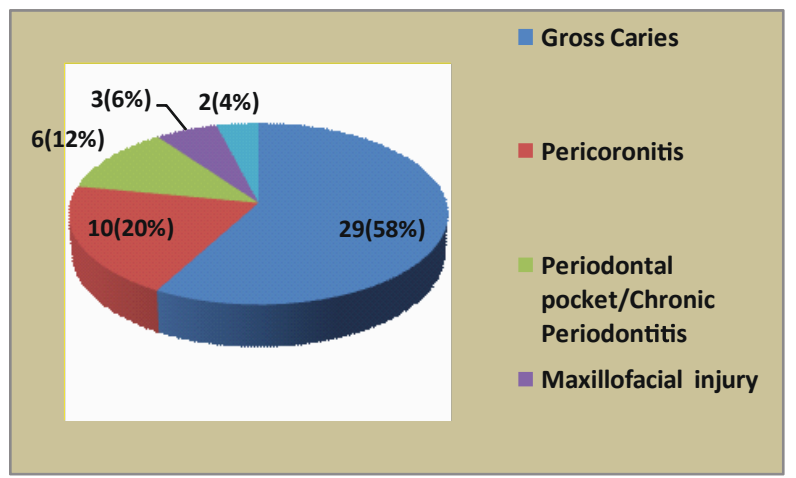

Fig-2: Distribution of causes of maxillofacial fascial space infections among the study population $(n=50)$

Fig-2 shows distribution of causes of maxillofacial fascial space infections among the study group. About 90\% (45 patients) maxillofacial infections were due to odontogenic causes and $6 \%$ (3 cases) were due to maxillofacial injuries and rest $4 \%$ (2 cases) were due to malignancies.

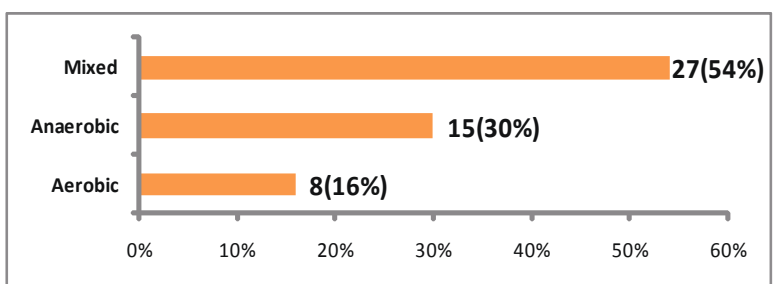

Fig-3: Distributions of microorganism types among the study group $(n=50)$ 
Fig-3 shows distribution of microorganism types among the study group. Among the 50 patients mixed type microorganisms were found in highest $27(54 \%)$ cases.

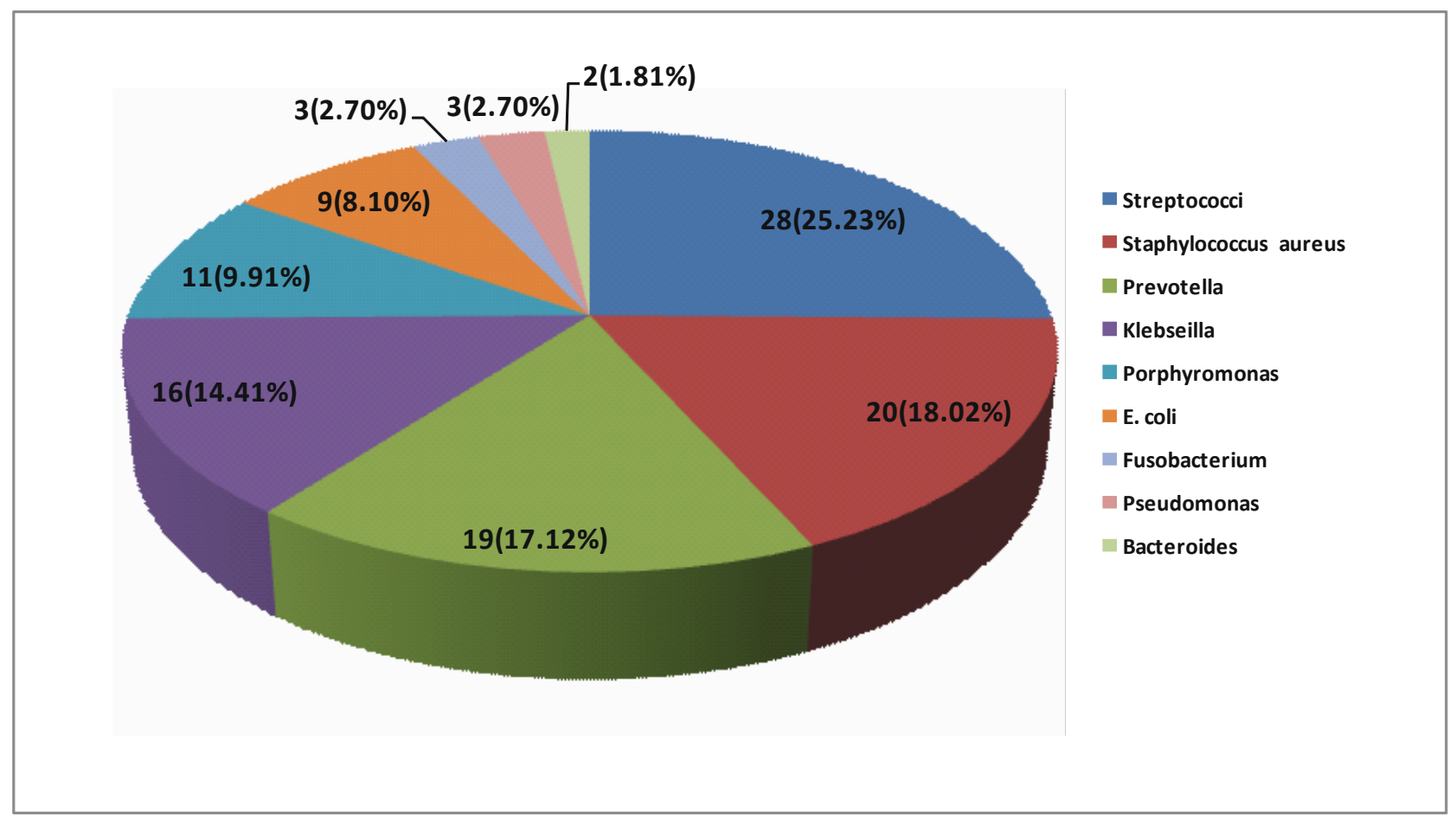

Fig-4: Differential counts of microorganisms from total isolates

Fig-4 shows distribution of microorganism specieses among all the 111 isolates. Streptococci, Staphylococci, Prevotella and Klebseilla were predominant in number.

Table-II: Antimicrobial sensitivity among all the isolated microorganisms

\begin{tabular}{|c|c|c|c|c|c|c|c|c|c|c|c|}
\hline Bacteria & Frequency & Amox & $\begin{array}{c}\text { Amox/ } \\
\text { Clav }\end{array}$ & Azithr & $\begin{array}{c}\text { Ceph / } \\
\text { Cephalex }\end{array}$ & $\begin{array}{l}\text { Cefix / } \\
\text { Ceftria }\end{array}$ & Cipro & Clinda & Eryth & Metro & Tetra \\
\hline Strept & 28 & $\begin{array}{c}60.72 \\
\%\end{array}$ & $\begin{array}{l}75 \\
\%\end{array}$ & $\begin{array}{c}67.86 \\
\%\end{array}$ & $\begin{array}{c}92.86 \\
\%\end{array}$ & $\begin{array}{l}50 \\
\%\end{array}$ & $\begin{array}{c}78.57 \\
\%\end{array}$ & $\begin{array}{c}89.29 \\
\%\end{array}$ & $\begin{array}{c}78.57 \\
\%\end{array}$ & $\begin{array}{l}00 \\
\%\end{array}$ & $\begin{array}{c}21.43 \\
\%\end{array}$ \\
\hline Staph & 20 & $\begin{array}{l}00 \\
\%\end{array}$ & $\begin{array}{l}35 \\
\%\end{array}$ & $\begin{array}{l}25 \\
\%\end{array}$ & $\begin{array}{l}75 \\
\%\end{array}$ & $\begin{array}{l}50 \\
\%\end{array}$ & $\begin{array}{l}30 \\
\%\end{array}$ & $\begin{array}{c}100 \\
\%\end{array}$ & $\begin{array}{l}60 \\
\%\end{array}$ & $\begin{array}{l}00 \\
\%\end{array}$ & $\begin{array}{l}00 \\
\%\end{array}$ \\
\hline Prev & 19 & $\begin{array}{c}79.05 \\
\%\end{array}$ & $\begin{array}{c}100 \\
\%\end{array}$ & $\begin{array}{c}63.16 \\
\%\end{array}$ & $\begin{array}{l}00 \\
\%\end{array}$ & $\begin{array}{l}00 \\
\%\end{array}$ & $\begin{array}{c}36.84 \\
\%\end{array}$ & $\begin{array}{c}100 \\
\%\end{array}$ & $\begin{array}{c}36.84 \\
\%\end{array}$ & $\begin{array}{c}100 \\
\%\end{array}$ & $\begin{array}{c}73.68 \\
\%\end{array}$ \\
\hline Kleb & 16 & $\begin{array}{l}00 \\
\%\end{array}$ & $\begin{array}{c}56.25 \\
\%\end{array}$ & $\begin{array}{c}31.25 \\
\%\end{array}$ & $\begin{array}{c}100 \\
\%\end{array}$ & $\begin{array}{c}100 \\
\%\end{array}$ & $\begin{array}{c}100 \\
\%\end{array}$ & $\begin{array}{c}31.25 \\
\%\end{array}$ & $\begin{array}{l}75 \\
\%\end{array}$ & $\begin{array}{c}100 \\
\%\end{array}$ & $\begin{array}{c}31.25 \\
\%\end{array}$ \\
\hline Porph & 11 & $\begin{array}{c}42.85 \\
\%\end{array}$ & $\begin{array}{c}57.15 \\
\%\end{array}$ & $\begin{array}{c}57.15 \\
\%\end{array}$ & $\begin{array}{c}21.43 \\
\%\end{array}$ & $\begin{array}{c}21.43 \\
\%\end{array}$ & $\begin{array}{c}21.43 \\
\%\end{array}$ & $\begin{array}{l}50 \\
\%\end{array}$ & $\begin{array}{l}50 \\
\%\end{array}$ & $\begin{array}{c}57.15 \\
\%\end{array}$ & $\begin{array}{c}35.72 \\
\%\end{array}$ \\
\hline E.coli & 09 & $\begin{array}{l}00 \\
\%\end{array}$ & $\begin{array}{l}00 \\
\%\end{array}$ & $\begin{array}{l}00 \\
\%\end{array}$ & $\begin{array}{c}100 \\
\%\end{array}$ & $\begin{array}{c}100 \\
\%\end{array}$ & $\begin{array}{c}77.77 \\
\%\end{array}$ & $\begin{array}{c}100 \\
\%\end{array}$ & $\begin{array}{l}00 \\
\%\end{array}$ & $\begin{array}{l}00 \\
\%\end{array}$ & $\begin{array}{l}00 \\
\%\end{array}$ \\
\hline Fuso & 03 & $\begin{array}{c}100 \\
\%\end{array}$ & $\begin{array}{c}100 \\
\%\end{array}$ & $\begin{array}{c}100 \\
\%\end{array}$ & $\begin{array}{l}00 \\
\%\end{array}$ & $\begin{array}{l}00 \\
\%\end{array}$ & $\begin{array}{l}00 \\
\%\end{array}$ & $\begin{array}{c}100 \\
\%\end{array}$ & $\begin{array}{c}100 \\
\%\end{array}$ & $\begin{array}{c}100 \\
\%\end{array}$ & $\begin{array}{l}00 \\
\%\end{array}$ \\
\hline Pseu & 03 & $\begin{array}{l}00 \\
\%\end{array}$ & $\begin{array}{c}100 \\
\%\end{array}$ & $\begin{array}{l}00 \\
\%\end{array}$ & $\begin{array}{l}00 \\
\%\end{array}$ & $\begin{array}{l}00 \\
\%\end{array}$ & $\begin{array}{l}00 \\
\%\end{array}$ & $\begin{array}{c}100 \\
\%\end{array}$ & $\begin{array}{l}00 \\
\%\end{array}$ & $\begin{array}{l}00 \\
\%\end{array}$ & $\begin{array}{c}100 \\
\%\end{array}$ \\
\hline Bact & 02 & $\begin{array}{l}00 \\
\%\end{array}$ & $\begin{array}{l}50 \\
\%\end{array}$ & $\begin{array}{c}100 \\
\%\end{array}$ & $\begin{array}{c}100 \\
\%\end{array}$ & $\begin{array}{c}100 \\
\%\end{array}$ & $\begin{array}{c}100 \\
\%\end{array}$ & $\begin{array}{c}100 \\
\%\end{array}$ & $\begin{array}{c}100 \\
\%\end{array}$ & $\begin{array}{c}100 \\
\%\end{array}$ & $\begin{array}{l}00 \\
\%\end{array}$ \\
\hline
\end{tabular}


Table-Il shows distribution of antimicrobial sensitivity among the 111 isolates. Streptococci showed highest sensitivity to Cephradine and Cephalexin (92.86\%) and highest resistance to Metronidazole (100\%). Staphylococci showed highest sensitivity to Clindamycin (100\%) and highest resistance to Amoxicillin, Metronidazole and Tetracycline (100\%). Prevotella showed highest sensitivity to Amoxiclave, Clindamycin and Metronidazole $(100 \%)$ and highest resistance to Cephalosporin. Klebseilla showed highest sensitivity to Cephalosporin and Ciprofloxacin and highest resistance to Amoxicillin and Metronidazole (100\%). Porphyromonas showed highest sensitivity to Amoxiclave, Azithromycin and Metronidazole $(57.15 \%)$ and highest resistance to Ciprofloxacin and Cephalosporin (78.57\%). E.coli showed highest sensitivity to Cephalosporin and Clindamycin (100\%), Ciprofloxacin (77.77\%) and resistance to all others (100\%). Fusobacteri showed highest sensitivity to all (100\%) except Cephalosporin, Tetracycline and Ciprofloxacin where resistance was $100 \%$. Pseudomonas showed highest sensitivity to Amoxiclave, Clindamycin and Tetracycline (100\%) all others were 100\% resistant. Bacteroides showed 100\% resistance to Amoxicillin and Tetracycline and $50 \%$ resistance to Amoxiclave and $100 \%$ sensitive to all others.

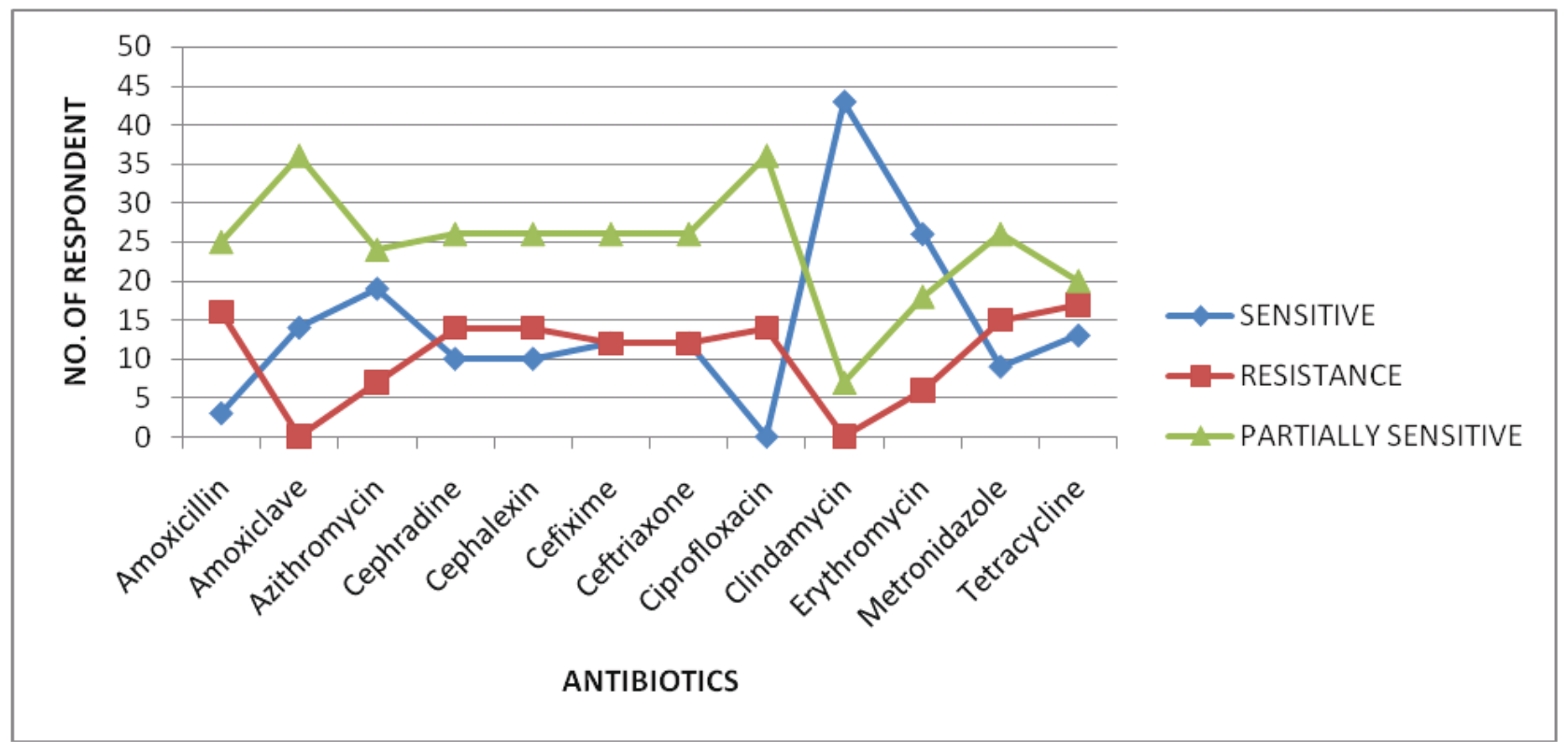

Fig-4: Antimicrobial sensitivity status among all the patients of the study group $(n=50)$

Figure-4 shows distribution of antibiotic sensitivity among the 50 patients. Clindamycin showed highest sensitivity among 45(90\%) patients, Erythromycin in 26 (52\%) patients, Azythromycin in 20(40\%) patients, Cefixime, Ceftriaxone and Tetracycline in $12 \%$ patients and Amoxiclave in $15 \%$ patients as a single drug therapy.

\section{Discussion}

The study revealed that highest $36 \%$ patients were between the ages of $15-25$ years and $26 \%$ patients were between the ages 26-35 years. Mean age was 34.18 and standard deviation (SD) was 14.37 . Therefore $62 \%$ patients were between the ages of 15-36 years. Among them $34(68 \%)$ were male and rest $16(32 \%)$ were female. So among the males prevalence of maxillofacial space infections were more. Those almost correlated with the findings of the studies conducted by Salinas et $\mathrm{al}^{8}$, Kohli et $\mathrm{al}^{22}$, and Sanchez et $\mathrm{al}^{23}$ where the highest number of maxillofacial fascial space infected population were below 40 years and male were predilected. In Kudiyirical et $\mathrm{al}^{24}$ studies, the mean age was 37 years and females were predominant $(52 \%)$. Whereas in Rega et $a^{21}$ study mean age of the population was 33 years and male were slightly predominant (54\%). But all those studies as well as present study indicated that patients between 15-45 years were more prone to maxillofacial fascial space infections.

In current study odontogenic infections were the main aetiological factor of maxillofacial fascial space infections in $90 \%$ cases. This correlated the study of Lambrecht and Dent ${ }^{13}$. Among those patients, gross caries was the 
main aetiological factor (58\%) and pericoronitis was the second highest $(20 \%)$ cause of maxillofacial fascial space infections. Whereas in Salinas et all ${ }^{8}$ study pericoronitis was the main aetiological factors among $67 \%$ patients and periapical disease due to gross dental caries was another aetiological factor of maxillofacial fascial space infections in rest $33 \%$ patients.

Among the 50 patients, 27(54\%) patients were affected by mixed i.e. both aerobic and anaerobic infections. $15(30 \%)$ patients were infected by only anaerobic and $08(16 \%)$ were infected only by aerobic microorganisms. Whereas $60 \%$ mixed, $33 \%$ anaerobic and $7 \%$ aerobic microorganisms were found in a study which was described in the text book of Peterson ${ }^{3}$. So the findings of present study were nearer to those of the second study. But the present study differed from Kohli et al ${ }^{46}$ study where highest $52.5 \%$ patients were affected by aerobic, $35 \%$ patients were affected by anaerobic and $12.5 \%$ patients were infected by mixed type microorganisms.

A total of 111 bacterial strains were isolated from 50 patients, accounting for 2.22 isolates per patient. Whereas Rega et $\mathrm{al}^{21}$ isolated on an average 2.6 microorganisms per patient and Salinas et al ${ }^{8}$ isolated on an average of 2.5 pathogens per sample. So the current study is very nearer to those studies in this aspect.

Rega et $\mathrm{al}^{21}$ found highest $28.99 \%$ Streptococci, then $21.2 \%$ Prevotella, $8.9 \%$ Staphylococci and $4.8 \%$ other microorganisms among all the aerobic and anaerobic isolates. In current study Streptococci was also found in highest number among all the aerobic and anaerobic microorganisms. It was $25.23 \%$ in number. Staphylococci $(18.02 \%)$ was 2 nd and Prevotella (17.12\%) was 3rd highest in number. Others were Klebseilla (14.41\%), Porphyromonas (9.91\%), E.coli (8.10\%), Fusobacterium(2.70\%), Pseudomonas (2.70\%) and Bacteroides (1.81\%). In 2003 Peterson $^{3}$ stated that, as Streptococci and other anaerobic bacteria are the most common causative microorganisms of maxillofacial fascial space infections. So during the selection of empirical antibiotics two things must be kept in mind. Firstly it must be effective against Streptococci and secondly the drug should be effective against wide range of anaerobes.
In the current study among the Streptococci the sensitivity status of first generation Cephalosporine i.e. Cephradine and Cephalexin was excellent. The chronological sensitivity rate from higher to lower order of different antibiotics were Cephradine and Cephalexin (92.86\%), Clindamycin (89.29\%), Ciprofloxacin and Erythromycin (78.57\%), Amoxicillin+ clavulanic acid (75\%), Azithromycin (67.86\%), Amoxicillin $(60.72 \%)$, Cefixime and Ceftriaxone $(50 \%)$, Tetracycline $(21.43 \%)$ and Metronidazole (0\%). So Metronidazole had no role against Streptococcus. But in Rega et al's (2006) study Streptococci exhibited highest 100\% sensitivity to Ciprofloxacillin, $98.4 \%$ sensitivity to Amoxicillin, $86.3 \%$ sensitivity to Clindamycin and $83.4 \%$ sensitivity to erythromycin. But Rahman et $\mathrm{al}^{25}$ study differed from both studies where Streptococci showed highest $85.7 \%$ sensitivity to Erythromycin.

Staphylococci exhibited highest sensitivity to Clindamycin (100\%). The chronological sensitivity rate from higher to lower order of different antibiotics were Cephradine and Cephalexin (75\%), Erythromycin (60\%), Amoxicillin+clavulanic acid (35\%), Azithromycin (25\%). They were absolutely resistant to Amoxicillin, Metronidazole and tetracycline. In the the study of Rega et $\mathrm{al}^{21}$ Staphylococci showed $95 \%$ sensitivity to Ciprofloxacin, $89.5 \%$ Clindamycin, and $75 \%$ sensitivity to Erythromycin.

Among the Prevotella the sensitivity of Amoxicillin+ clavulanic acid, Clindamycin and Metronidazole were excellent. The chronological sensitivity rate from higher to lower order of different antibiotics were Amoxicillin+clavulanic acid, Clindamycin and Metronidazole (100\%), Amoxicillin (79.05\%), Tetracycline (73.68\%), Azithromycin (63.16\%), Ciprofloxacin and Erythromycin (36.84\%), Cephalosporines $(00 \%)$ So Cephalosporine had no effect against Prevotella. In the study of Adebayo et al (2010) 10 Prevotella showed $100 \%$ sensitivity to Ciprofloxacin, $82.4 \%$ sensitivity to tetracycline and $64.7 \%$ to Erythromycin. Salinas et al $^{8}$ found $50 \%$ sensitivity to Erythromycin, and Tetracycline, $75 \%$ sensitivity to Amoxicillin and Amoxicillin-Clavulanic acid, 25\% sensitivity to Metronidazole, $75 \%$ sensitivity to Clindamycin and Azithromycin. Klebseilla exhibited $100 \%$ sensitivity to all Cephalosporine and Ciprofloxacin. The chronological sensitivity rate from higher to lower order of other antibiotics were Erythromycin (75\%), Amoxicillin+Clavulanic acid 
(56.25\%), Azithromycin, Clindamycin and Tetracycline (31.25\%), Amoxicillin and Metronidazole $(00 \%)$. But in Salinas et al ${ }^{8}$ study, Klebseilla showed highest $81.81 \%$ sensitivity to Clindamycin, $78.2 \%$ sensitivity to Amoxicillin and Amoxiclave, 69\% sensitivity to Tetracycline, $60 \%$ to Azithromycin and $58.2 \%$ sensitivity to Erythromycin.

The sensitivity state of Porphyromonas is unsatisfactory. Azithromycin, Metronidazole and Amoxicillin -Clavulanic acid showed highest sensitivity. It was $57.15 \%$. The chronological sensitivity rate from higher to lower order of other antibiotics were Clindamycin and Erythromycin 50\%, Amoxicillin $42.85 \%$, Tetracycline $35.72 \%$, Cephalosporin and Ciprofloxacin $21.43 \%$ whereas Salinas et al ${ }^{8}$ found $83 \%$ sensitivity to Erythromycin, $67 \%$ sensitivity to Tetracyclne, $83 \%$ sensitivity to Amoxicillin, and Amoxicillin-Clavulanic acid, 33\% sensitivity to Metronidazole, $83 \%$ sensitivity to Clindamycin and $75 \%$ sensitivity to Azithromycin.

In current study E.coli showed $100 \%$ sensitivity to Cephalosporin and Clindamycin and $77.77 \%$ sensitivity to Ciprofloxacin. And all others were found $100 \%$ resistant to it. Pseudomonas exhibited $100 \%$ sensitivity to Amoxicillin-Clavulanic acid, Clindamycin, Tetracycline and $100 \%$ resistant to all others. But in Salinas et al ${ }^{8}$ study both of them showed highest $81.81 \%$ sensitivity to Clindamycin, $78.2 \%$ sensitivity to Amoxicillin and Amoxiclave, $69 \%$ sensitivity to Tetracycline, $60 \%$ to Azithromycin and $58.2 \%$ sensitivity to Erythromycin.

Bacteroides showed $100 \%$ sensitivity to Azithromycin, Cephalosporine, Ciprofloxacin, Clindamycin, Erythromycin and Metronidazole, 50\% sensitivity to Amoxicillin-Clavulanic acid and $100 \%$ resistant to Amoxicillin and Tetrecycline. Whereas Salinas et $\mathrm{al}^{8}$ found $52 \%$ sensitivity to Erythromycin, $70 \%$ sensitivity to Tetracycline, $76 \%$ sensitivity to Amoxicillin and Amoxicillin-Clavulanic acid 6\% sensitivity to Metronidazole, $79 \%$ sensitivity to Clindamycin and $78 \%$ sensitivity to Azithromycin. Penicillin, Clindamycin and Amoxicillin-Clavulanic acid were very effective against Streptococci and Metronidazole was very effective against wide range of anaerobes. So Metronidazole in combination with any one of those antibiotics may be a very effective empirical antibiotic regimen against maxillofacial fascial space infections. Current study revealed that Amoxicillin-Clavulanic acid is more or less sensitive to all the isolates except E.coli which was $100 \%$ sensitive to Cephalosporine and $77.77 \%$ sensitive to Ciprofloxacin. Almost similar findings were found in Salinas et $a^{8}$ study where Amoxicillin, AmoxicillinClavulanic acid, Tetracycline and Clindamycin were found highly sensitive to maxillofacial fascial space infections regardless of the origins. So Combination of Amoxicillin-Clavulanic acid and any Cephalosporine may be a very effective empirical antibiotic regimen. Again Ciprofloxacin was found sensitive against all the aerobes and anaerobes except Fusobacterium and Pseudomonas which were 100\% sensitive to Amoxicillin-Clavulanic acid. So Amoxicillin-Clavulanic acid and Ciprofloxacin combination therapy may be another empirical antibiotic regimen against maxillofacial fascial space infection.

Present study also revealed that in 45 patients $(90 \%)$ Clindamycin was the single antibiotic to be effective against all the causative microorganisms. So Clindamycin may be single empirical antibiotic to treat maxillofacial space infections. The second highest effective single antibiotic was Erythromycin. It was effective in around 52\% (26 patients) cases. So Erythromycin may be another single empirical antibiotic of choice. The third one was Azithromycin which was absolutely sensitive in $40 \%$ (in 20 patients) patients.

\section{Conclusion}

The study revealed that Streptococcus (25.23\%), Staphylococcus (18.02\%), and Prevotella (17.12\%) were the main causative microorganisms of maxillofacial fascial space infections. Others were Klebseilla (14.41\%), Porphyromonas (9.91\%), E.Coli (8.10\%), Fusobacterium and Pseudomonas (2.70\%) and Bacteroides (1.81\%). Though their sensitivity status against the most available and economic antimicrobial agents was not satisfactory but still few less used antibiotics like Clindamycin and Erythromycin showed good sensitivity to those. Any of those may be single empirical antibiotic to treat the maxillofacial fascial space infections otherwise combination therapy by two broad spectrum antimicrobial agents like Amoxicillin-Clavulanic acid with Cephalosporine or Ciprofloxacillin may be a very effective empirical antimicrobial therapy. Clindamycin or Erythromycin may be a good alternative in case of Penicillin sensitivity. 
Metronidazole had no action against aerobes and it can be prescribed only when anaerobes are suspected i.e. maxillofacial fascial space infections associated with highly necrosed tissue and diminished blood supply. As odontogenic infections were found to be the main aetiological factors of maxillofacial fascial space infections which can be very well prevented by proper oral hygiene instruction, regular dental checkup and early management of dental caries and periodontal diseases. Current study also reflected a very alarming scenario regarding the sensitivity status among the maxillofacial fascial space infection patients against the available antimicrobial agents. So the patients must be advised, guided and monitored to take the medicine in proper dosages and frequencies. Many of our patients are found to possess the tendency to discontinue the medicine just after symptomatic relief and before completion of total dosages. That is the prime suspected cause of development of antimicrobial resistance.

\section{References}

1. Rajendaran R, Sivapathasundaram B. Shafer's Textbook of Oral Pathology. 6th ed. New Delhi: Elsivier 2009; 501-14.

2. Balagi SM. Text Book of Oral and Maxillofacial Surgery. 1st ed. New Delhi: Elsevier 2007; 116-63.

3. Peterson JL. Contemporary Oral and Maxillofacial Surgery. 4th ed. St. Louis, Missouri: Mosby. 343-66.

4. Malik AN. Text Book of Oral and Maxillofacial Surgery. 2nd ed. New Delhi: Jaypee Brothers. 587-680.

5. Brook I. Antibiotic Resistance of Anaerobic Bacteria. American Society for Microbiology 2009; 61(8):873-99.

6. Cawson RA, Odell EW. Cawson's Essential of Oral Pathology and Oral Medicine. 8th ed. London; Elsivier 2008; 99-112.

7. Howe LG. Minor Oral Surgery. 3rd ed. London: Wright $1985 ; 124-249$.

8. Salinas MB, Riu NC, Atyes LB, et al. Antibiotic Susceptibility of the Bacteria Causing Odontogenic Infections. Med Oral Patol Oral Cir Bucal 2006; 11:70-5.

9. Jardim JR, Landuci LF, Oliveira KLD, et al. Microbiota Associated with Infections of the Jaws. International Journal of Dentistry 2012; 12(2):1-8.

10. Adewolu OF, Adebayo O, Alli O, et al. Bacteriology of Orofacial Infections in Gamia, Nigeria. Academia Arena 2010; 2(12):82-4.
11. Zheng $L$, Yang $C$, Zhang $W$, et al. Is there association between severe multispace infections of the Oral and Maxillofacial region and diabetes? American Association Oral and Maxillofacial Surgeon 2011; 7(10):1-7.

12. Pandit N, Chhabra S, Chababra N, et al. Cellulitis Caused by Unusual Calculus Deposition : A Case Report .Journal of Oral Health Society 2011; 2(2):31-5.

13. Lambrecht TJ, Dent M. Antibiotic Prophylaxis and Therapy in Oral and Maxillofacial Surgery. Quintessence International 2007; 38(8):689-97.

14. Kapoor V. Text Book of Oral and Maxillofacial Surgery. 2nd ed. New Delhi: Arya (Medi) Publishing House 2004; 138-79.

15. Martinez GR, Balleste IC, Vias JMH, et al. Antibiotic prescription in the treatment of odontogenic infection by health professionals: A factor to consensus. Med Oral Patol Oral Bucal 2012; 17(3):452-6.

16. Ulaibau IC, Januay T, Goss AN. Severe odontogenic infections. Austrilian Dental Journal Medications Supplement 2005; 50(2):874-82.

17. Alaluusua S, Veerkamp J, Declerck D. Policy Document for the Use of Antibiotics in Paediatric Dentisrey. European Academy of Paediatric Dentistry 2002; 7(2):1-16.

18. Brook I. Anaerobic Infection in Childhood. PJMID 1985; 14(2):45-51.

19. Nwaokorie FO, Ogunsola FT, Coker AO. Betalactamase production in anaerobic bacteria. RIF 2010; 1(3):122-79.

20. Brook I. Encapsulated Anaerobic Bacteria in Synergistic Infections. American Society for Microbiology 1986; 50(4):452-7.

21. Rega AJ, Aziz SR, Ziccardi VB. Microbiology and Antibiotic Sensitivities of Head and Neck Infections of Odontogenic Origin. J Oral Maxllofac Surg 2006; 5(64):1377-80.

22. Kohli M, Mathur A, Siddiqui SR. In vitro evaluation of microbiological flora of orofacial infections. J Maxillofac Oral Surg 2009; 8(4):329-33.

23. Sannchez R, Mirada E, Arias J, et al. Severe Odontogenic Infection: Epidemiological, Microbiological and Therapeutic Factors. Med Oral Patol Oral Cir Buccal 2011; 16(5):670-6.

24. Kudiyirickal MG. Hollinshed F. Clinical profile of orofacial infections: An experience from two primary care dental practice. Med Oral Patol Oral Cir Bucal 2012; 17(4):533-7.

25. Rahman ZAA, Hassan $H$, Bunyarit SS. Bacteriology of orofacial infection. Asian Journal of Oral and Maxillofacial Surgery 2005; 17(3):168-72. 